\title{
Laboratory Investigation into Early-Age Strength Improvement of Cold Recycled Asphalt Mixture Containing Asphalt Emulsion and Cement
}

\author{
Yinfei Du, ${ }^{1}$ Lingxiang Kong, ${ }^{2}$ and Tangzhong Wei $\mathbb{D D}^{3}$ \\ ${ }^{1}$ School of Civil Engineering, Central South University, Changsha 410075, China \\ ${ }^{2}$ Key Laboratory of Traffic Safety on Track, Ministry of Education, School of Traffic and Transportation Engineering, \\ Central South University, Changsha 410075, China \\ ${ }^{3}$ Nanjing Xingyou Transportation Technology Co. Ltd., Nanjing 211100, China
}

Correspondence should be addressed to Tangzhong Wei; hhweitangzhong@163.com

Received 16 November 2018; Revised 11 March 2019; Accepted 5 May 2019; Published 12 June 2019

Academic Editor: Zahid Hossain

Copyright (c) 2019 Yinfei Du et al. This is an open access article distributed under the Creative Commons Attribution License, which permits unrestricted use, distribution, and reproduction in any medium, provided the original work is properly cited.

Cold recycled asphalt mixture (CRAM) has been reported to be able to provide a cleaner method to rehabilitate damaged asphalt pavement. This work used the CRAM containing emulsified asphalt (AE) and cement to investigate the methods of improving its early-age strength by considering mixture composition, including the types of $\mathrm{AE}$ and cement and the contents of $\mathrm{AE}$, cement, and moisture. The curing conditions, such as temperature and humidity, were also involved. The results show that the mixture should be carefully designed to determine optimum $\mathrm{AE}$ and moisture content. Also, high cement content was helpful to increase the early-age strength. By changing the curing environment, it was found that raising curing temperature and applying a relatively low humidity contributed to the early-age strength improvement. The interaction of cement hydration and AE demulsification was investigated using microimage and laboratory experiments. The results show that AE particles were easy to cluster because of the negative ions released by cement hydration. AE delayed the early cement hydration but improved the later intensity of cement hydration. The coupling effect of AE and cement resulted in higher early-age strength than those of the mixtures only with cement or only with AE. The results presented in this work are expected to give guidance for preparing a CRAM with high earlyage strength.

\section{Introduction}

After several years' service, asphalt pavement tends to generate a series of distresses, such as rutting, cracking, pothole, and so on. Maintenance is required to restore sound service quality. When the distresses are severe or even when the pavement structure is destroyed, milling the asphalt pavement and replacing it, which is also called recycled asphalt pavement (RAP), is always used. Compared with hot recycled asphalt pavement, cold recycled asphalt mixture (CRAM) can help produce a cleaner environment, including less raw aggregate mining, less fossil fuel consumption, and lower carbon footprint [1-3]. Besides, some other wastes, including copper slag [4], steel slag [5], and coal waste $[6,7]$, were used in the mixture, which further contributed to protecting the environment.

It was reported that CRAM was often used in the base layer of heavy-traffic pavement [8-10]. The low early-age strength of CRAM needs a long curing period and thus affects pavement construction efficiency [11], because the top layer should be placed after the CRAM reaches a sufficient strength requirement. The CRAM can also be placed in the top layer of low traffic volume road, and the low earlyage strength will delay the time of traffic opening [12]. Especially for the CRAM constructed in winter or cold regions, early-age distresses might appear due to the low strength of this mixture. In addition, the early-age strength was often used to predict the long-term strength of CRAM 
$[13,14]$. It is, therefore, necessary to investigate the early-age strength improvement of this mixture.

Many factors can influence the early-age strength of CRAM. Cement, lime [15], and other additives [16] have been reported to be able to accelerate strength development. Besides, improving compaction method [17] and curing conditions $[18,19]$ could also take effect. For the CRAM with asphalt emulsion (AE) and cement, raising curing temperature could accelerate the demulsification process of $\mathrm{AE}$ and the hydration process of cement, thus increasing the early-age strength. Limited studies focused on the methods of improving the early-age strength of this kind of mixture $[8,20-22]$.

This work aims at systematically investigating the earlyage strength evolution of CRAM by considering many influencing factors. Different types or contents of AE, cement, and moisture were added to the CRAM to determine an optimized mixture composition. The curing conditions, including temperature and humidity, were also involved to find a proper curing environment. According to the strength evolution characteristics, the CRAM with high early-age strength can be prepared. The interaction between cement hydration and AE demulsification is analyzed using microimages and laboratory experiments, which is expected to help further understand the strength developing mechanism of CRAM.

\section{Materials and Experimental Program}

2.1. Materials. A Pen 70 base asphalt was used to prepare cationic slow setting AE [23], which was used to mix aggregate. Its constitution and properties are shown in Table 1. Two types of RAP material with particle size ranging from $0-9.5 \mathrm{~mm}$ and $9.5-31.5 \mathrm{~mm}$, together with raw aggregate, were gathered to form a continuous gradation, as shown in Figure 1. The two types of RAP material contained $5.32 \mathrm{wt} . \%$ and 4.56 wt. $\%$ asphalt, respectively. The default AE content of all the mixture specimens was $4.0 \%$, except for some specified demonstrations. For example, when studying the effect of AE content on the early-age strength of CRAM, there were total of seven contents of AE. The moisture content of the CRAM included two parts: added free water and the water in the AE. The content of added free water was 2.3\% except those mixtures in Section 3.1.3.

To accelerate the strength development, three types of cement, including ordinary Portland cement, sulphoaluminate cement, and slag Portland cement, were used in this study. The default cement content of all the mixture specimens was $2 \%$. In order to study the influence of cement content on the strength development, the amounts of the cement added to the mix were set to be $1 \%, 1.5 \%, 2 \%, 3 \%$, and $4 \%$ by weight of the mixture, respectively.

2.2. Specimen Preparation. All the required materials, including RAP, cement, mineral powder, premix water, and $\mathrm{AE}$, were mixed using a laboratory mixer. The loose mix was compacted to form cylindrical specimens with a diameter of $150 \mathrm{~mm}$ and a height of $95 \pm 2.0 \mathrm{~mm}$ using a Superpave
TABle 1: Properties of AE.

\begin{tabular}{lcc}
\hline Index & Test result & Requirement \\
\hline Particle surface electric charge & Cationic & Cationic \\
Emulsifier content $(\%)$ & 3.0 & - \\
Asphalt content $(\%)$ & 63.0 & $>62$ \\
Water content $(\%)$ & 34 & - \\
Evaporation residue & & \\
$\quad$ Penetration $\left(25^{\circ} \mathrm{C}, 100 \mathrm{~g}, 5 \mathrm{~s}\right) / 0.1 \mathrm{~mm}$ & 69.5 & $50-300$ \\
$\quad$ Ductility $\left(15^{\circ} \mathrm{C}, 5 \mathrm{~cm} / \mathrm{min}\right)(\mathrm{cm})$ & 65.5 & $>40$ \\
$\quad$ Softening temperature $\left({ }^{\circ} \mathrm{C}\right)$ & 49.5 & - \\
Storage stability $(\%)$ & & \\
$\quad 1 \mathrm{~d}$ & 0.1 & $<1$ \\
$5 \mathrm{~d}$ & 1.3 & $<5$ \\
\hline
\end{tabular}

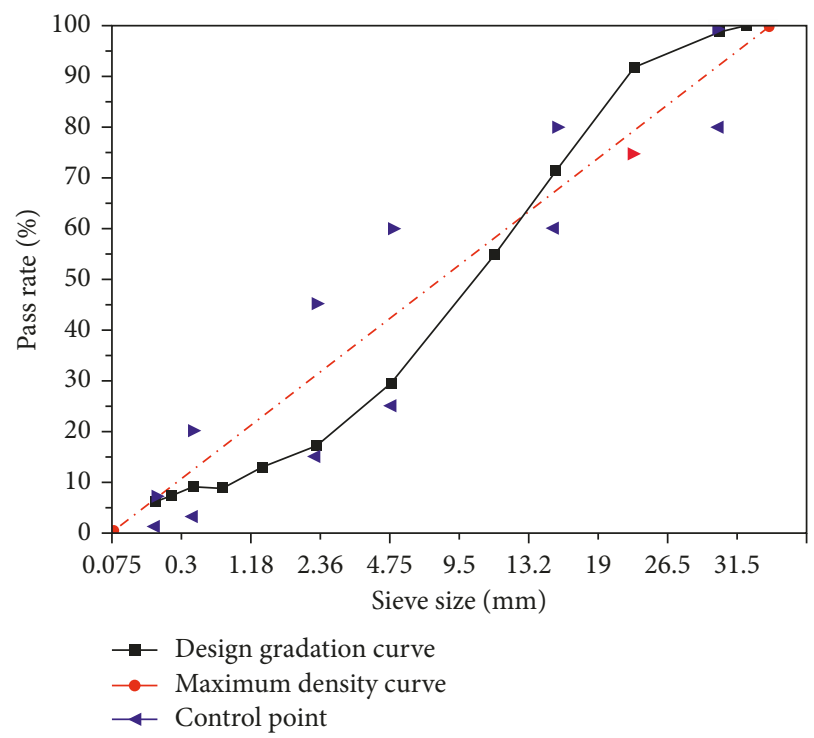

FIgURE 1: Aggregate gradation curve of CRAM.

gyratory compactor with 30 gyrations. Then, the compacted specimens were wrapped with plastic film to simulate the field pavement environment. Finally, the wrapped specimens were put into a curing room.

In the curing room, the temperature and humidity were varied to investigate their influences on strength development. The temperature was set to be $0^{\circ} \mathrm{C}, 10^{\circ} \mathrm{C}, 20^{\circ} \mathrm{C}, 30^{\circ} \mathrm{C}$, and $60^{\circ} \mathrm{C}$, respectively, and the humidity was set to be $55 \%$ and $95 \%$, respectively. The curing process of the specimen is shown in Figure 2.

In order to find the interaction effect between $\mathrm{AE}$ and cement under a microscope, different kinds of $\mathrm{AE} /$ cement mortars were prepared. When observing the dynamic behavior of cement in $\mathrm{AE}$, about 5\% Portland cement was added in AE solution with emulsifier (A). When studying the effect of $\mathrm{AE}$ on cement hydration, 2-5\% AE was added in cement paste $($ cement/water $=0.4)$.

\subsection{Test Methods}

2.3.1. Indirect Tensile Strength (ITS) Test. This study used ITS as an indicator to characterize the strength development 


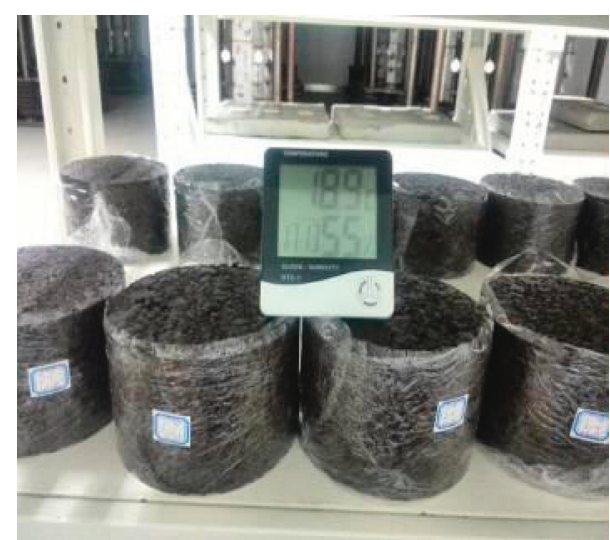

Figure 2: Specimen curing process.

influenced by many factors. The indirect tensile test was performed at $20^{\circ} \mathrm{C}$. The specimens were subjected to a varying load at a vertical displacement rate of $50 \mathrm{~mm} / \mathrm{min}$ until the specimen was damaged.

2.3.2. Microscopic Test. An L-UEPI optical microscope (Nikon Co. Ltd., Japan) was used to observe the dynamic behavior of cement in AE. A Quanta 250 environment scanning electron microscope (ESEM) (FEI Co. Ltd., America) was used to characterize the surface microstructure of cement mortar and cement/AE mortar.

2.3.3. Isothermal Calorimeter Test. A TAM AIR isothermal calorimeter (TA Co. Ltd., America) was used to acquire the process of cement hydration of cement mortar and cement/ $\mathrm{AE}$ mortar. The test temperature was $20^{\circ} \mathrm{C}$. After the mortar was prepared, the probe was placed into the mortar to detect the heat release rate.

2.4. Experimental Program. For clearly illustrating the influencing factor, mixture composition, and corresponding evaluating indicator, a comprehensive experiment program is shown in Table 2.

\section{Early-Age Strength Developing Characteristic}

The various components (e.g., cement, $\mathrm{AE}$, and moisture contents), together with different curing conditions (e.g., time, temperature, and humidity), influence the early-age strength development of CRAM. So, investigating the above influences and concluding some strategies will help improve the earlyage strength of this mixture, thus beneficial for early traffic opening or early construction of the upper layer.

\subsection{Influences of Material Components on Early-Age Strength Development}

3.1.1. Cement. Six contents and three types of cement were added in the CRAM to investigate their influences on the early-age strengths during a curing period of 1-7 days. In the mixture specimens with different types of cement, a constant cement content of $1.5 \%$ was added. The results are shown in Figures 3 and 4, respectively.

Figure 3 illustrates that the early-age strength of CRAM increased with curing time. However, the mixture without cement addition presented a very slow strength increasing trend. The mixture with $4 \%$ cement content had a 7 -day ITS of $1.01 \mathrm{MPa}$, which was almost ten times higher than that of the mixture without cement, indicating that cement had a significant influence on strength improvement. We can also find that the strength of the mixture with higher cement content had a higher strength increasing rate during the curing period of 1-3 days. During this period, the strength of the mixtures with $0-4 \%$ cement increased by $3.1,1.2,1.3,2.1,2.6$, and 2.3 times, respectively. This result indicates that the CRAM had a very high strength increasing rate in the early curing period.

It can be found from Figure 4 that cement type had an influence on the early-age strength of CRAM. For the strength at different curing periods, the mixture with sulphoaluminate cement was the highest among the three kinds of mixture, while the mixtures with the other two kinds of cement had almost equal strengths at different curing periods. The reason for this conclusion is that sulphoaluminate cement belongs to a kind of rapid hardening cement. In order to improve the early-age strength of CRAM, it is suggested to add sulphoaluminate cement into CRAM.

3.1.2. Asphalt Emulsion. The properties of AE with emulsifier (A) (AE (A)) have been shown in Table 1. Seven contents of this kind of $\mathrm{AE}$ and another four types of $\mathrm{AE}$ were added into the CRAM to investigate their influences on the early-age strength at the curing time of 3 days and 7 days, respectively. The results are shown in Figures 5 and 6, respectively.

Different from the increasing strength with increasing cement content, there was an optimum $\mathrm{AE}$ content to generate the maximum strength. According to the data shown in Figure 5, when the AE content was $4 \%$ by weight of the total mixture, the 3-day and 7-day ITSs were up to $0.28 \mathrm{MPa}$ and $0.41 \mathrm{MPa}$. The two strength values were both higher than those of the mixtures with 3\% and 5\% AE. Take the 3-day strength, for example. The strength of CRAM with $4 \% \mathrm{AE}$ was $7 \%$ and $25 \%$ higher than those of the CRAM with $3 \%$ and $5 \% \mathrm{AE}$, respectively. The result indicates that it is essential to perform a careful mixture design to determine AE content to get improved early-age strength.

As shown in Figure 6, AE type had an influence on the early-age strength of CRAM. The 3-days and 7-day ITSs presented similar trends. The ITS of the CRAM with emulsifier (A) lied in the middle of the five CRAMs. Take the strength, for example. The 7-day strength of the CRAM with $\mathrm{AE}(\mathrm{C})$ was $0.37 \mathrm{MPa}$, which was $15.9 \%$ lower than that of the CRAM with AE (E). From the above analysis, it can be found that it is important to select a proper emulsifier to prepare CRAM.

3.1.3. Moisture. In the mixture design process, water was added to produce an easily compacted mixture and provide a 
TABLe 2: Experimental program.

\begin{tabular}{|c|c|c|c|c|}
\hline \multicolumn{3}{|c|}{ Influencing factor } & Mixture composition & Evaluating indicator \\
\hline $\begin{array}{l}\text { Mixture } \\
\text { composition }\end{array}$ & $\begin{array}{c}\text { Cement } \\
\text { AE } \\
\text { Moisture }\end{array}$ & $\begin{array}{l}\text { Six contents } \\
\text { Three types } \\
\text { Seven contents } \\
\text { Five types } \\
\text { Ten contents }\end{array}$ & 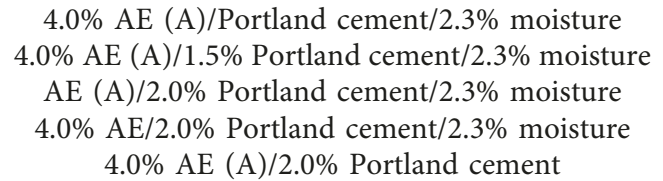 & ITS and air voids content \\
\hline Curing condition & & $\begin{array}{l}\text { nperature } \\
\text { umidity } \\
\text { iting time }\end{array}$ & $4.0 \% \operatorname{AE}(\mathrm{A}) / 2.0 \%$ Portland cement $/ 2.3 \%$ moisture & $\begin{array}{l}\text { ITS and residual moisture content } \\
\text { ITS and residual moisture content } \\
\text { ITS and air voids content }\end{array}$ \\
\hline
\end{tabular}

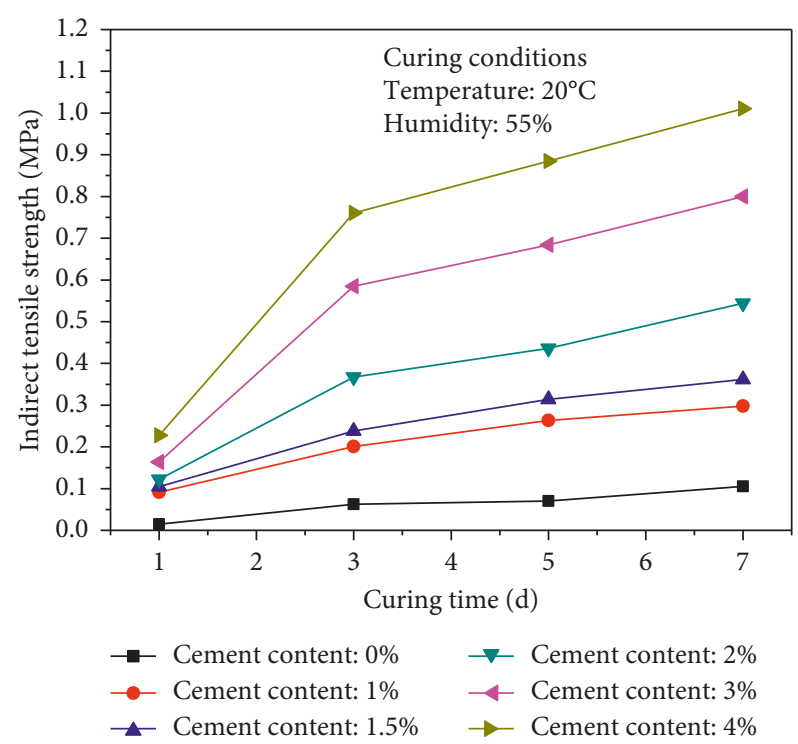

Figure 3: Variations of early-age strength with different cement contents.

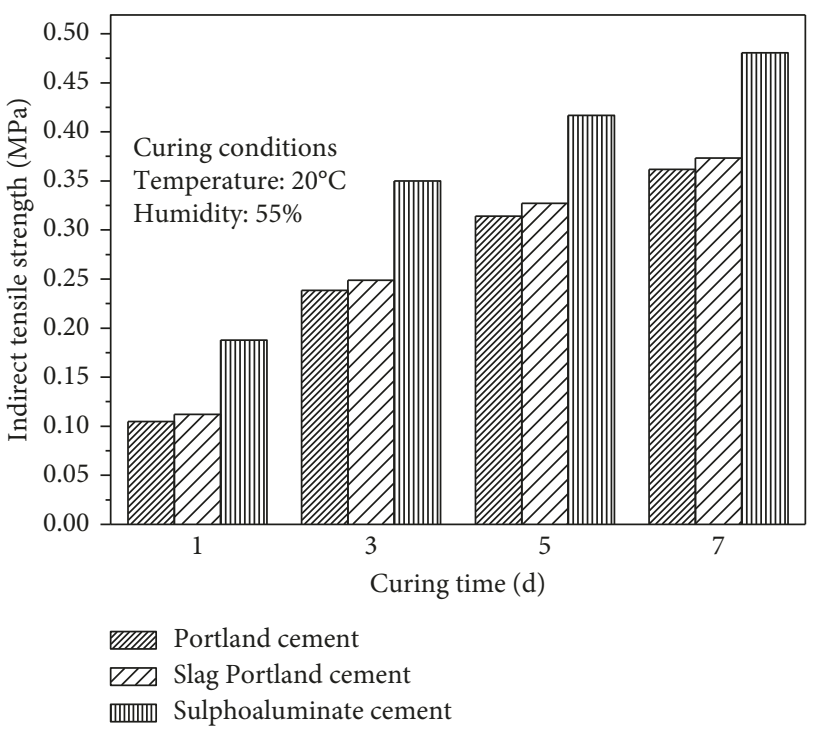

FIGURE 4: Variations of early-age strength with different cement types.

water source for cement hydration. The moisture content here included the added free water and the water in AE. Total ten moisture contents were used to investigate the

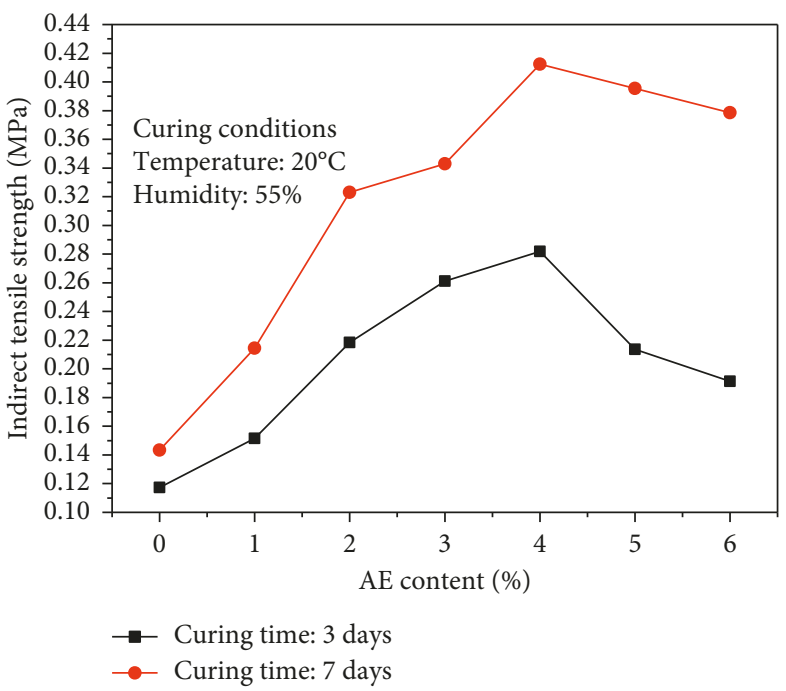

Figure 5: Variations of early-age strength with different $\mathrm{AE}$ contents.

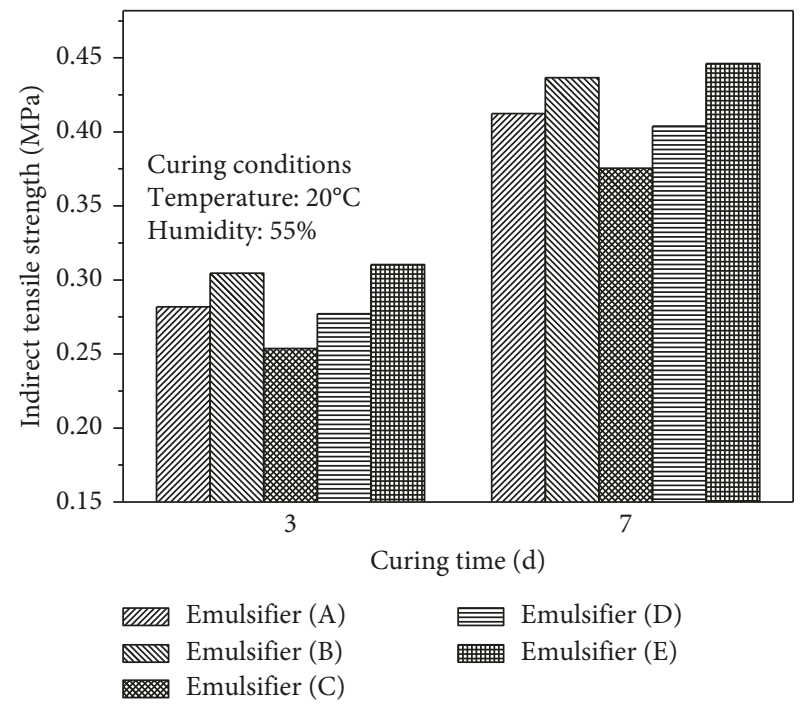

FIGURE 6: Variations of early-age strength with different AE types.

evolutions of strength and air voids. The results are shown in Figure 7.

Around $4.2 \%$ moisture content in the mixture at the curing times of 3 days and 7 days both presented the maximum strengths, while there was a minimum air voids 


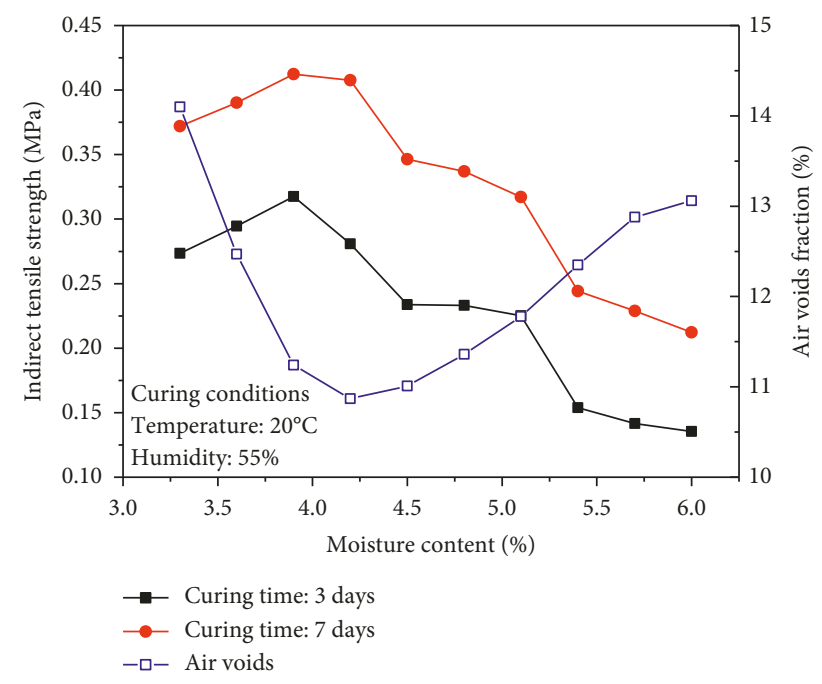

FIGURE 7: Variations of early-age strength and air void content with different moisture contents.

content at this moisture content. When the moisture content was lower than $4 \%$, the insufficient aggregate wetting and uneven distribution of AE resulted in the mixture hard to be compacted. By contrast, when the moisture content was higher than $4 \%$, the flow of $\mathrm{AE}$ and the "spring state" in the compaction process led to the high air voids content of the mixture. Because of the large air void content, the mixture showed an overall low strength.

\subsection{Influences of Curing Environment on Early-Age Strength Development}

3.2.1. Temperature. The curing temperature can influence cement hydration and AE demulsification, thus having an influence on strength evolution. The combined effect of cement hydration and AE demulsification simultaneously affects the residual moisture content in the mixture. The results of early-age strength and residual moisture content at different temperatures are shown in Figures 8 and 9, respectively. It should be noted that the residual moisture included the water consumed for cement hydration. This part of water was considered into the mixture mass.

At $0^{\circ} \mathrm{C}$, the early-age ITS increased very slowly, which was because at this temperature, cement hydration and $\mathrm{AE}$ demulsification progressed in very low speeds. The result indicates that it should be forbidden to place CRAM in winter. With temperature rising, the above two processes accelerated and the strength thus increased quickly. When the curing temperature changed from $30^{\circ} \mathrm{C}$ to $60^{\circ} \mathrm{C}$, the strength-developing trend changed a lot. The 7-day strength at the temperature of $60^{\circ} \mathrm{C}$ was twice higher than that at the temperature of $30^{\circ} \mathrm{C}$, indicating that raising the curing temperature could greatly contribute to the early-age strength.

Overall, the residual moisture content varied in an opposite trend with curing time, compared to the early-age strength, because water had a higher evaporating rate at a

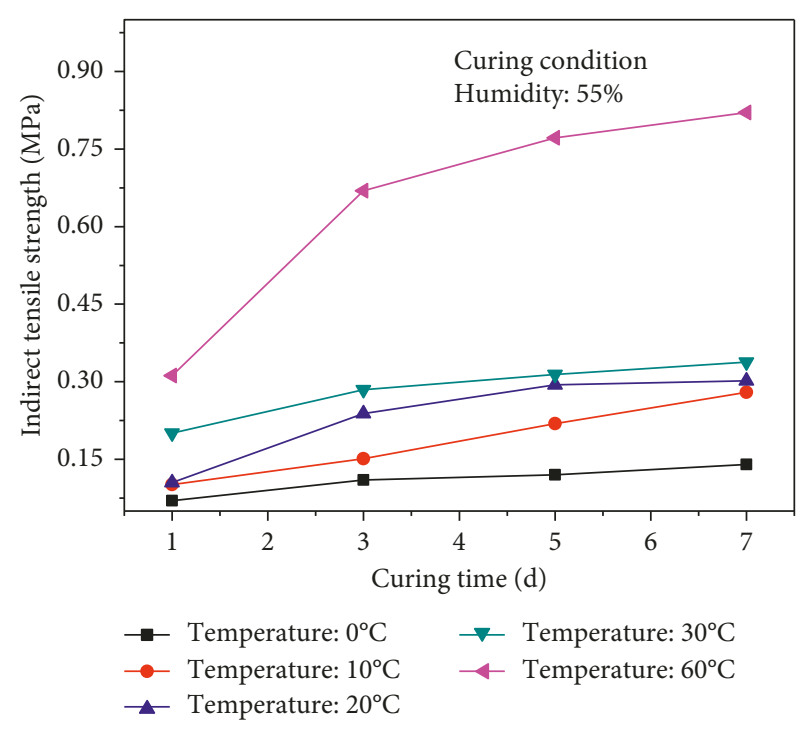

Figure 8: Variations of early-age strength with curing temperatures.

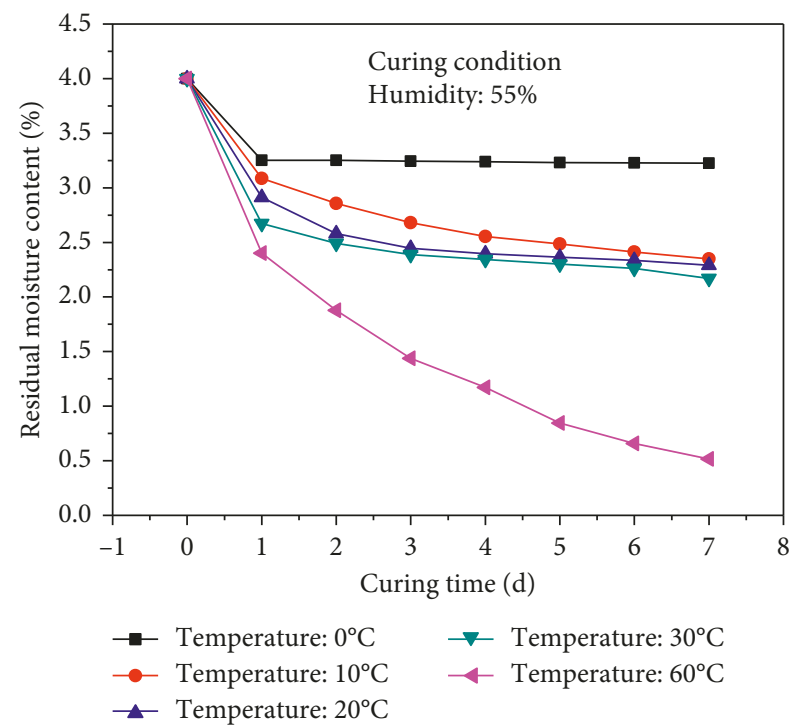

FIgURE 9: Variations of residual moisture content with curing temperatures.

higher temperature. Higher water evaporating efficiency generally led to faster strength development of CRAM.

3.2.2. Humidity. From Figure 9, we can find that residual moisture content decreased with increased strength, indicating that the moisture content in the mixture affected its strength development. In order to investigate the above effect in detail, two curing humidity conditions of 55\% and $95 \%$ were made, and the variations of ITS (curing time of 0-28 days) and corresponding residual moisture content were recorded, as shown in Figure 10.

Figure 10 shows that the ITS reduced with increasing curing humidity, and the strength difference between the two curing humidity enlarged with increasing curing time. 


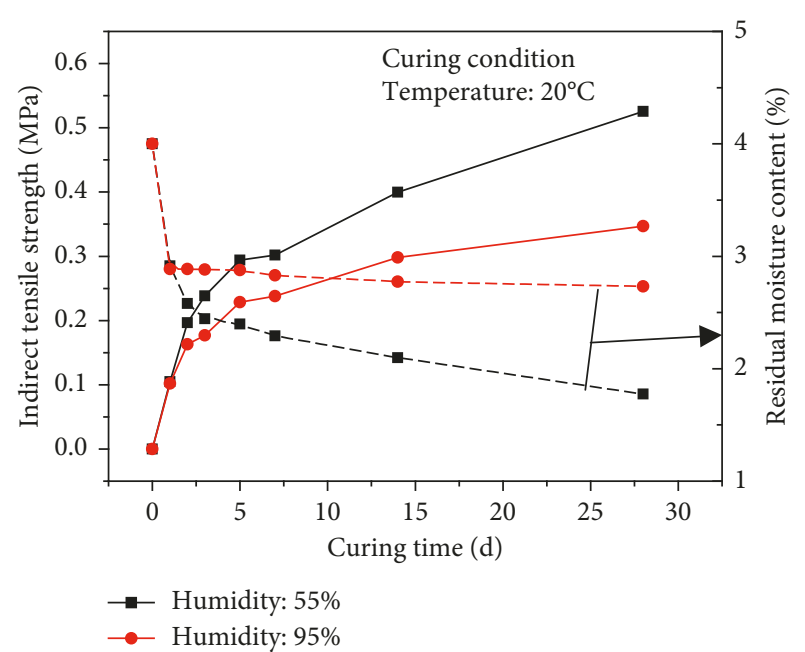

FIGURE 10: Variations of early-age strength and residual moisture content with curing humidity.

The 7-day and 28-day strengths of the mixture in the curing humidity of $55 \%$ were $25.2 \%$ and $51.3 \%$ higher than those in the curing humidity of $95 \%$, respectively.

The residual moisture content had an opposite trend with curing time compared with ITS. Although all the mixture specimens were wrapped with plastic films around, the moisture content in specimen decreased with curing time. This is because the moisture was due to the free water evaporation from the upper surface of the specimen.

3.2.3. Waiting Time. The waiting time refers to the period from plant mixing to in situ placement and compaction for cold central-plant recycled mixture or the period from in situ mixing to compaction for cold in-place recycled mixture. To discuss the influence of waiting time on strength development is helpful to make a reasonable plan in in situ construction of CRAM. The results are shown in Figure 11.

Figure 11 obviously illustrates that waiting time had a negative influence on strength development. With increasing waiting time, the moisture in the specimen evaporated gradually, which resulted in less free water that could help mixture compaction. In addition, AE particles began to break, leading to more difficult compactibility. It should also be noted that cement gradually hydrated with increasing waiting time. The hydration products before compaction could not fill in the internal air voids in the compacted mixture, which also led to high air void content.

\section{Interaction between Cement and $\mathrm{AE}$}

It was reported that cement was added in the CRAM to improve its early-age strength [15], which also validated by the results in Figures 3 and 4 . AE provided the other adhesive effect between loose particles (e.g., RAP and aggregate). Investigating the interactions between these two bonding materials provides a guide to further understand the strength developing mechanism.

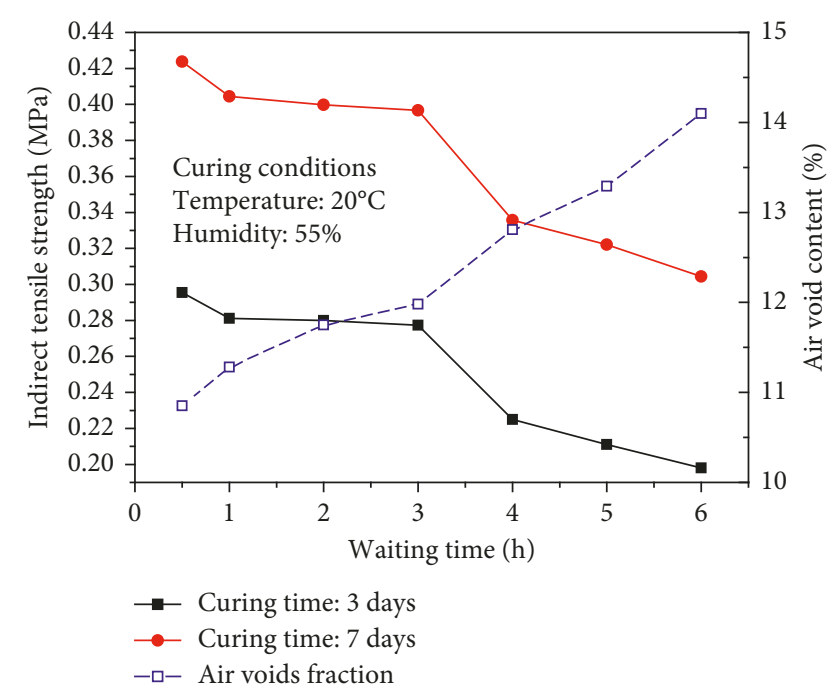

FIGURE 11: Variation of early-age strength and air void content with working time.

4.1. Combined Effect of Cement and AE in the Development of Early-Age Strength. Three mixtures with the same aggregate gradation and three kinds of bonding materials (both with cement and $\mathrm{AE}$, only with $\mathrm{AE}$, and only with cement) were prepared to investigate the combined effect of cement and $\mathrm{AE}$ in the development of early-age strength. For the mixture only with $\mathrm{AE}$, cement was replaced by limestone filler based on the concept of equal volume. For the mixture only with cement, the water in $\mathrm{AE}$ was supplemented by adding more water during mixing. The "Sum" in Figure 12 was equal to the strength of the mixture only with $\mathrm{AE}$ and the strength of the mixture only with cement.

The strength comparison of the mixtures only with $\mathrm{AE}$ and only with cement indicates that cement had a higher influence on very early-age strength than $\mathrm{AE}$, while the strength of the mixture only with $\mathrm{AE}$ gradually increased with curing time. It can be found that the strength of control mixture was higher than that of "Sum," indicating that the interaction between cement and $\mathrm{AE}$ is beneficial for the early-age strength improvement of the mixture. The 7-day and 14-day strength values of control mixture were $39.7 \%$ and $37.3 \%$ higher than those of "Sum," respectively.

4.2. Dynamic Behavior of Cement in AE. In order to observe the dynamic behavior of cement in $\mathrm{AE}$, a series of optical image comparison of $\mathrm{AE} / \mathrm{cement}$ mortar were performed. The prepared mortar was placed under the scope of an optical microscope. The images that were magnified by 40 times were captured according to the time requirement. The results are shown in Figure 13.

Figures 13(a) and 13(b) show that AE particles are evenly distributed in $\mathrm{AE}$ solution. With time prolonging, $\mathrm{AE}$ was gradually demulsified. By contrast, AE began to cluster around cement in a very short time when cement was added. And, the cluster phenomenon gradually strengthened with time, as shown in Figure 13(d). Simultaneously, the dispersed AE particles also clustered because of cement addition. The above phenomenon was attributed to negative 


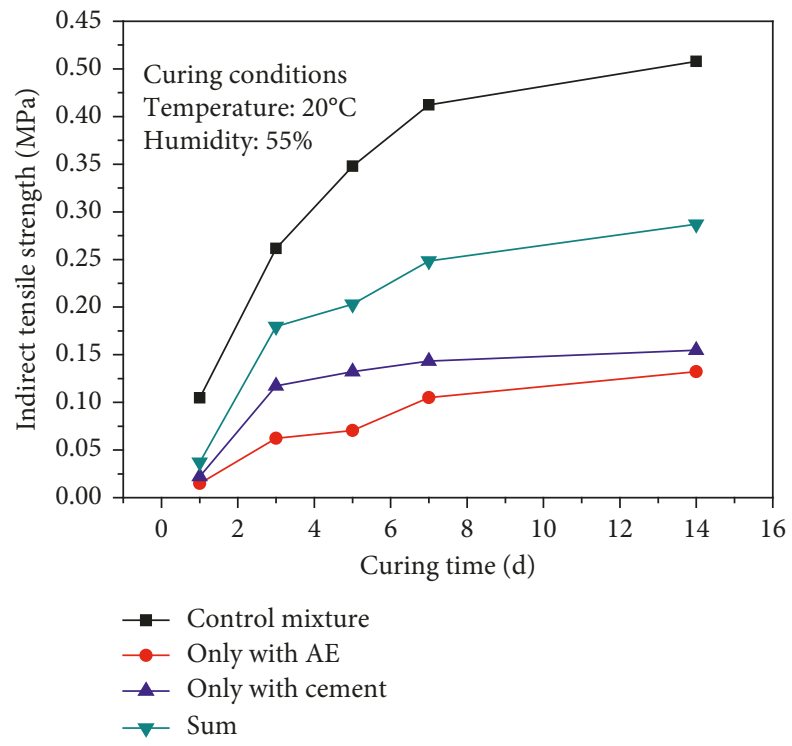

FIGURE 12: Early-age strength developing process under different bonding conditions.

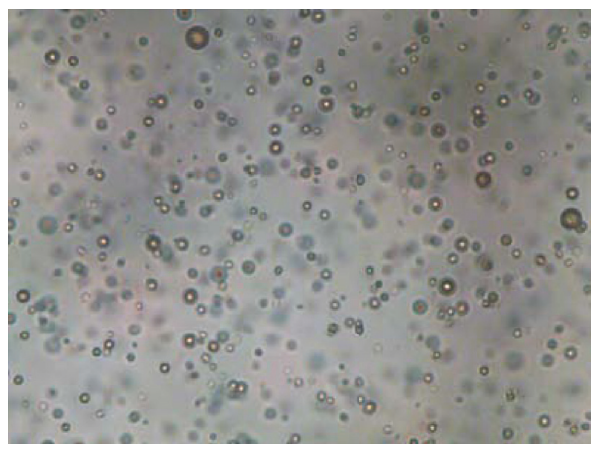

(a)

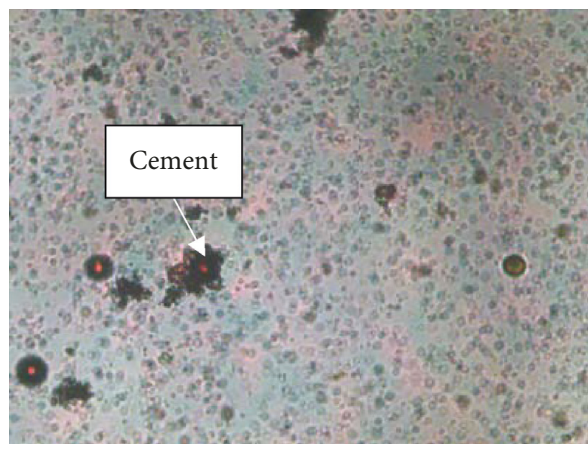

(c)

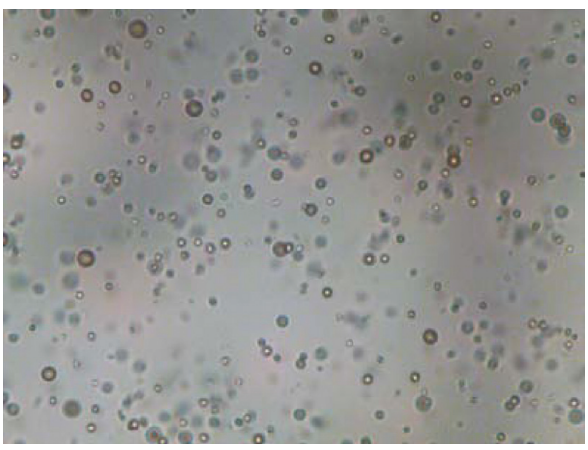

(b)

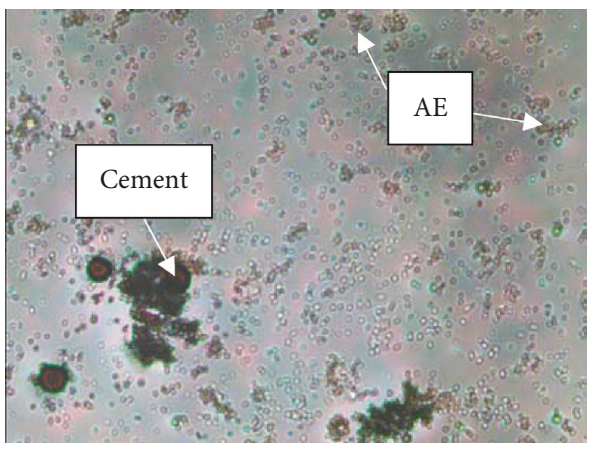

(d)

FIgURE 13: Dynamic images: (a) AE solution (1 min); (b) AE solution (10 min); (c) cement/AE composite (1 min); (d) cement/AE composite (10 min).

ions released by cement hydration, which caused AE particles' attraction and clustering with each other.

\subsection{Effect of AE on Cement Hydration}

4.3.1. Heat Release Rate. The heat release rate curve of cement/AE mortar was used to investigate the effect of $\mathrm{AE}$ on cement hydration. The results are shown in Figure 14.
It can be seen from Figure 14(a) that AE delayed the overall hydration process. Figure 14(b) could quantitatively illustrate the induction period delayed by the addition of AE. The induction period of cement hydration was extended from $1 \mathrm{~h}$ to nearly $18 \mathrm{~h}$ when $5 \% \mathrm{AE}$ was added into cement. We can also find that the peak heat release rate of cement/AE mortar increased. As AE content increased, more water was introduced, which provided more opportunities for cement hydration. 


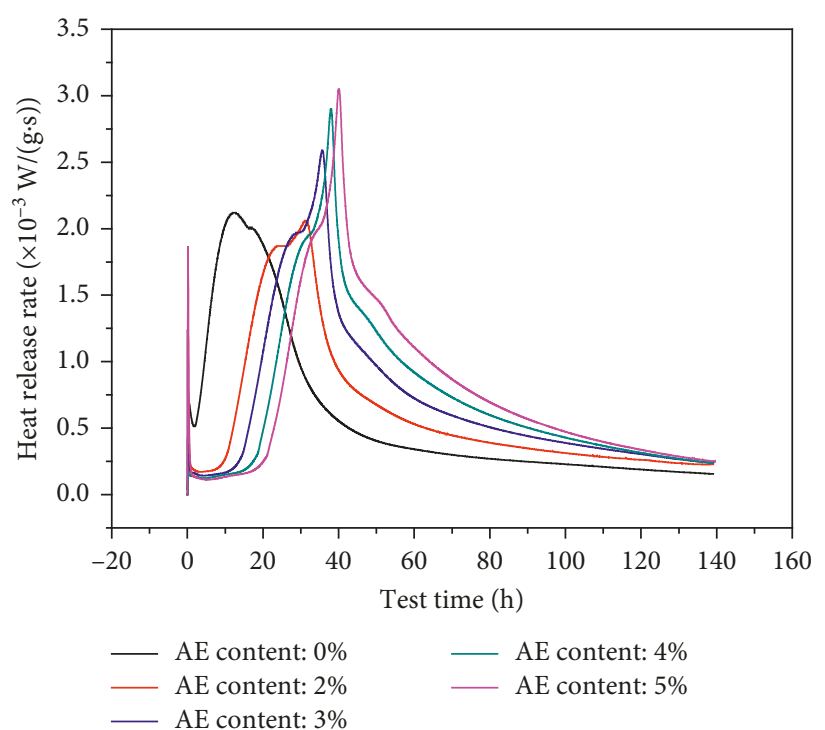

(a)

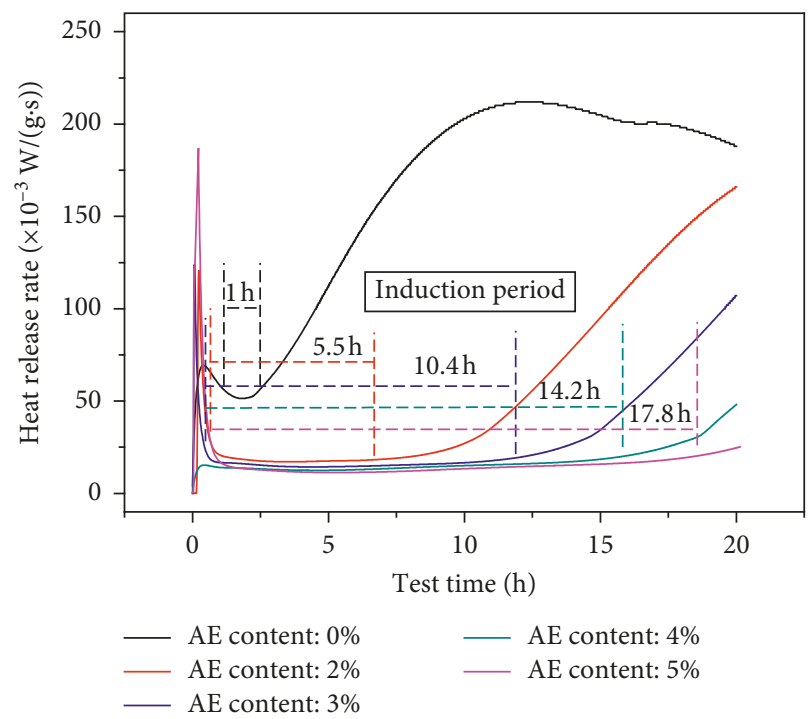

(b)

FIgURE 14: Cement hydration curves with different AE contents.

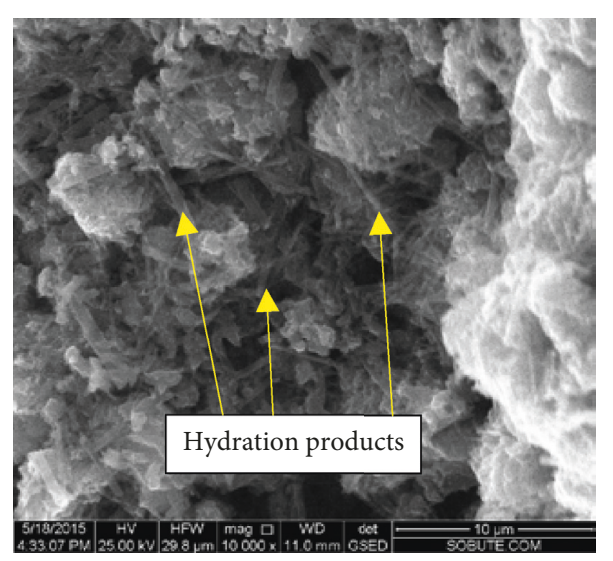

(a)

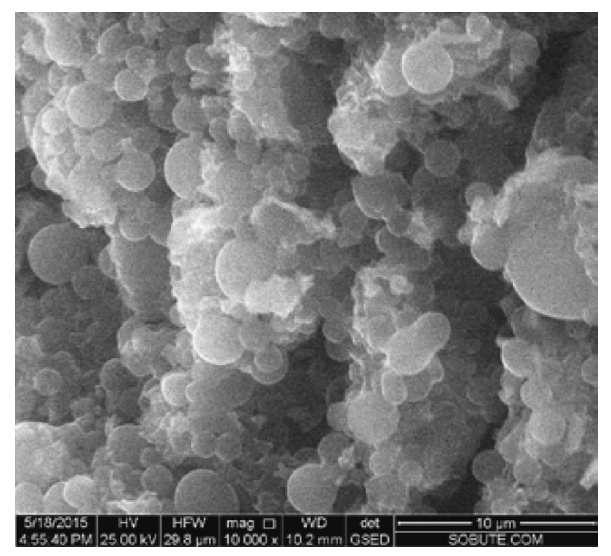

(c)

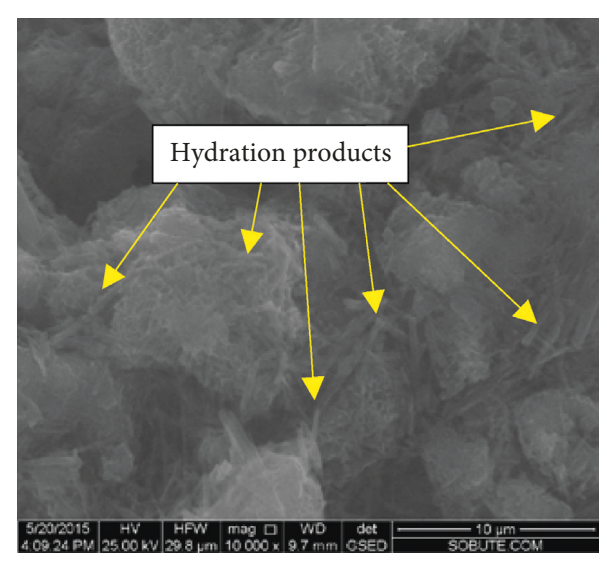

(b)

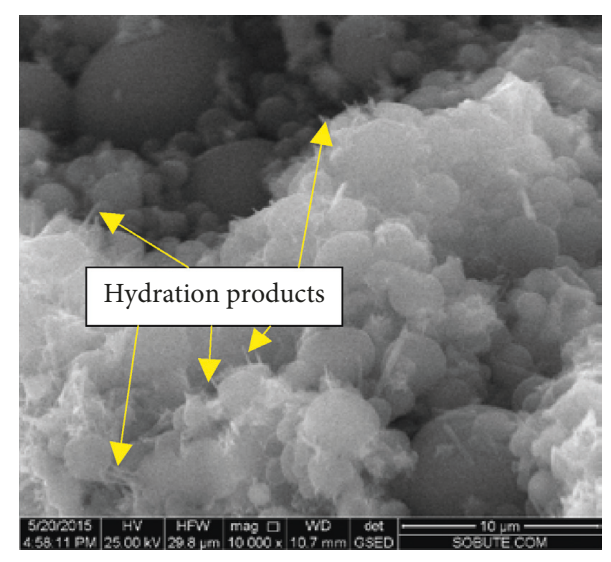

(d)

FIGURE 15: ESEM images: (a) cement mortar (5 days); (b) cement mortar (7 days); (c) cement/AE mortar (5 days); (d) cement/AE mortar (7 days). 
4.3.2. ESEM Image. ESEM images of cement and cement/ AE mortar at the curing time of 5 days and 7 days were captured, as shown in Figure 15. All the images were magnified by 10000 times.

There have been many cement hydration products in the 5-day cement mortar, as shown in Figure 15(a). Two days later, there was no obvious change of cement hydration products. By contrast, there were very few hydration products in the cement/AE mortar at the curing time of 5 days. However, many hydration products appeared on the surfaces of spherical AE particles, as shown in Figure 15(d). The results indicate that $\mathrm{AE}$ delayed the process of cement hydration.

\section{Conclusions}

Compared with hot recycled asphalt mixture, cold recycled asphalt mixture (CRAM) could save more energy consumption. However, the early-age strength of this mixture is vital to early traffic opening of newly rehabilitated pavement. This work investigated the influences of a series of factors, including mixture composition and curing environment, on the early-age indirect tensile strength (ITS) of CRAM containing asphalt emulsion (AE) and cement.

Increasing cement content, combined with using fast hardening cement (e.g., sulphoaluminate cement), could increase the ITS of CRAM. However, it should be noted that there were optimum $\mathrm{AE}$ and moisture contents to ensure the high ITS. AE type also had an influence on the ITS. Curing environment, such as temperature and humidity, influenced the ITS as well. Raising curing temperature dramatically increased the ITS, because of the high water evaporating, AE demulsification, and cement hydration rates. The humidity result shows that $55 \%$ humidity was superior to $95 \%$ humidity in improving the ITS. It was necessary to shorten the period during mixture mixing to compaction to get a high ITS.

The interaction of cement hydration and AE demulsification was investigated by performing microimages and laboratory experiments of the CRAM or cement/AE mortar. It was found that $\mathrm{AE}$ particles were easy to cluster due to the negative ions released by cement hydration. Although AE addition delayed cement hydration, a phenomenon of higher heat release rate in cement hydration was observed. The results show that the coupled effect of cement and AE helps to develop higher early-age strength, compared with the mixture or mortar only with cement or only with AE.

\section{Data Availability}

The data used to support the findings of this study are available from the corresponding author upon request.

\section{Conflicts of Interest}

The authors declare that they have no conflicts of interest.

\section{Acknowledgments}

This work was financially supported by the National Natural Science Foundation of China (no. 51808562) and Highway
Technology Project of Zhejiang Highway Administration, China (no. 2019H11).

\section{References}

[1] T. Ma, H. Wang, Y. L. Zhao, X. M. Huang, and Y. H. Pi, "Strength mechanism and influence factors for cold recycled asphalt mixture," Advances in Materials Science and Engineering, vol. 2015, Article ID 05016002, 10 pages, 2015.

[2] L. P. Thives and E. Ghisi, "Asphalt mixtures emission and energy consumption: a review," Renewable and Sustainable Energy Reviews, vol. 72, pp. 473-484, 2017.

[3] B. Yu, S. Wang, and X. Gu, "Estimation and uncertainty analysis of energy consumption and $\mathrm{CO}_{2}$ emission of asphalt pavement maintenance," Journal of Cleaner Production, vol. 189, pp. 326-333, 2018.

[4] A. Behnood, M. Modiri Gharehveran, F. Gozali Asl, and M. Ameri, "Effects of copper slag and recycled concrete aggregate on the properties of CIR mixes with bitumen emulsion, rice husk ash, Portland cement and fly ash," Construction and Building Materials, vol. 96, pp. 172-180, 2015.

[5] M. Ameri and A. Behnood, "Laboratory studies to investigate the properties of CIR mixes containing steel slag as a substitute for virgin aggregates," Construction and Building Materials, vol. 26, no. 1, pp. 475-480, 2012.

[6] A. Modarres, M. Rahimzadeh, and M. Zarrabi, "Field investigation of pavement rehabilitation utilizing cold in-place recycling," Resources, Conservation and Recycling, vol. 83, no. 1, pp. 112-120, 2014.

[7] M. A. Omrani and A. Modarres, "Emulsified cold recycled mixtures using cement kiln dust and coal waste ashmechanical-environmental impacts," Journal of Cleaner Production, vol. 199, pp. 101-111, 2018.

[8] J. T. Lin, J. X. Hong, and Y. Xiao, "Dynamic characteristics of $100 \%$ cold recycled asphalt mixture using asphalt emulsion and cement," Journal of Cleaner Production, vol. 156, pp. 337-344, 2017.

[9] A. Modarres and P. Ayar, "Coal waste application in recycled asphalt mixtures with bitumen emulsion," Journal of Cleaner Production, vol. 83, pp. 263-272, 2014.

[10] C. Sangiorgi, P. Tataranni, A. Simone, V. Vignali, C. Lantieri, and G. Dondi, "A laboratory and filed evaluation of Cold Recycled Mixture for base layer entirely made with Reclaimed Asphalt Pavement," Construction and Building Materials, vol. 138, pp. 232-239, 2017.

[11] P. Ayar, "Effects of additives on the mechanical performance in recycled mixtures with bitumen emulsion: an overview," Construction and Building Materials, vol. 178, pp. 551-561, 2018.

[12] F. Xiao, S. Yao, J. Wang, X. Li, and S. Amirkhanian, "A literature review on cold recycling technology of asphalt pavement," Construction and Building Materials, vol. 180, pp. 579-604, 2018.

[13] J. Yan, Z. Leng, F. Li, H. Zhu, and S. Bao, "Early-age strength and long-term performance of asphalt emulsion cold recycled mixes with various cement contents," Construction and Building Materials, vol. 137, pp. 153-159, 2017.

[14] B. Dolzycki, M. Jaczewski, and C. Szydlowski, "The long-term properties of mineral-cement-emulsion mixtures," Construction and Building Materials, vol. 156, pp. 799-808, 2017.

[15] Y. Niazi and M. Jalili, "Effect of Portland cement and lime additives on properties of cold in-place recycled mixtures with asphalt emulsion," Construction and Building Materials, vol. 23, no. 3, pp. 1338-1343, 2009. 
[16] Y. Wang, Z. Leng, X. Li, and C. Hu, "Cold recycling of reclaimed asphalt pavement towards improved engineering performance," Journal of Cleaner Production, vol. 171, pp. 1031-1038, 2018.

[17] L. Gao, F. Ni, S. Charmot, and H. Luo, "Influence on compaction of cold recycled mixes with emulsions using the Superpave gyratory compaction," Journal of Materials in Civil Engineering, vol. 26, no. 11, article 04014081, 2014.

[18] A. Graziani, C. Godenzoni, F. Cardone, and M. Bocci, "Effect of curing on the physical and mechanical properties of coldrecycled bituminous mixtures," Materials and Design, vol. 95, pp. 358-369, 2016.

[19] Y. Kim, S. Im, and H. D. Lee, "Impacts of curing time and moisture content on engineering properties of cold in-place recycling mixtures using foamed or emulsified asphalt," Journal of Materials in Civil Engineering, vol. 23, no. 5, pp. 542-553, 2011.

[20] L. Gao, F. Ni, C. Ling, and J. Yan, "Evaluation of fatigue behavior in cold recycled mixture using digital image correlation method," Construction and Building Materials, vol. 102, pp. 393-402, 2016.

[21] C. Godenzoni, A. Graziani, E. Bocci, and M. Bocci, "The evolution of the mechanical behaviour of cold recycled mixtures stabilised with cement and bitumen: field and laboratory study," Road Materials and Pavement Design, vol. 19, no. 4, pp. 856-877, 2018.

[22] Y. Kim and H. D. Lee, "Performance evaluation of Cold InPlace Recycling mixtures using emulsified asphalt based on dynamic modulus, flow number, flow time, and raveling loss," KSCE Journal of Civil Engineering, vol. 16, no. 4, pp. 586-593, 2012.

[23] P. Saberi and E. Kashi, "Evaluating oxide shell performance of hot-rolled steel as an additive in bitumen," International Journal of Nanoscience and Nanotechnology, vol. 14, no. 3, pp. 229-239, 2018. 


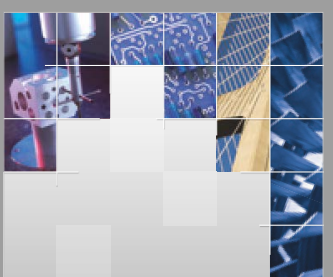

\section{Enfincering}
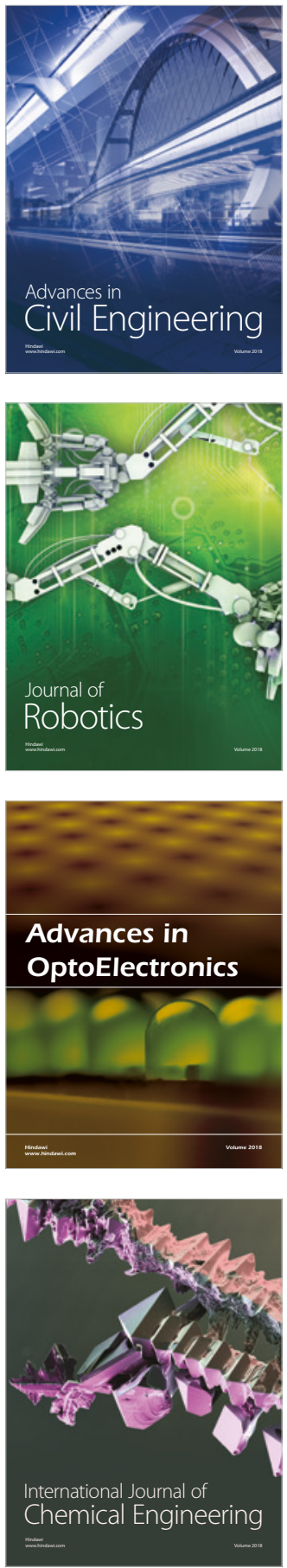

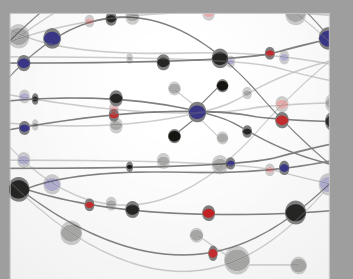

\section{Rotating \\ Machinery}

The Scientific World Journal

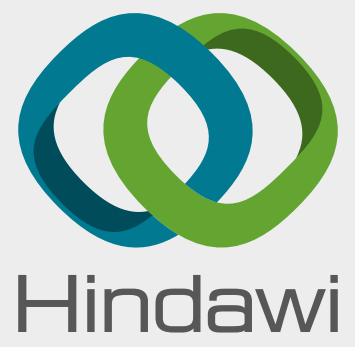

Submit your manuscripts at

www.hindawi.com
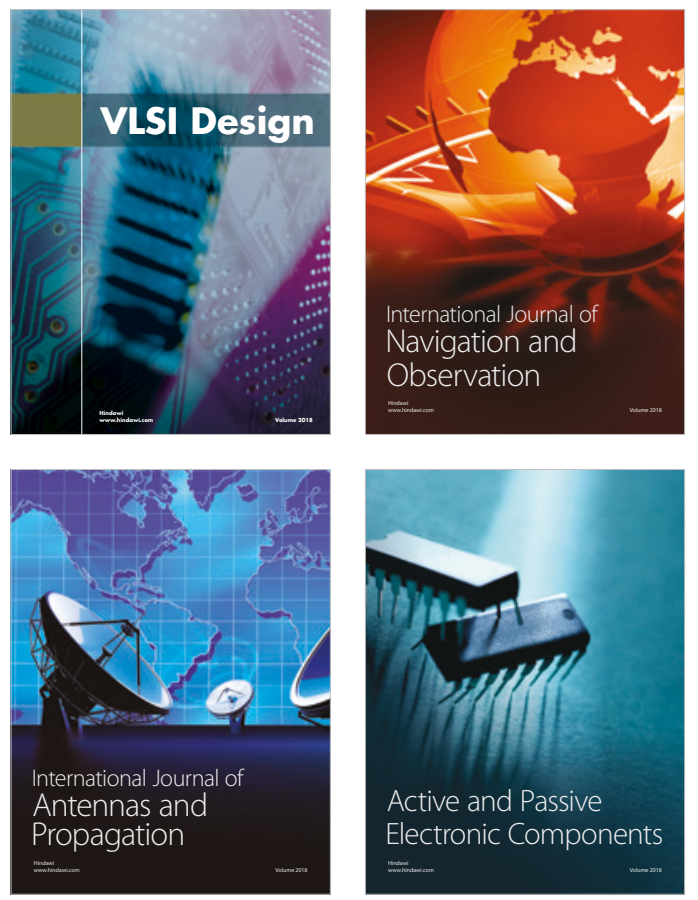
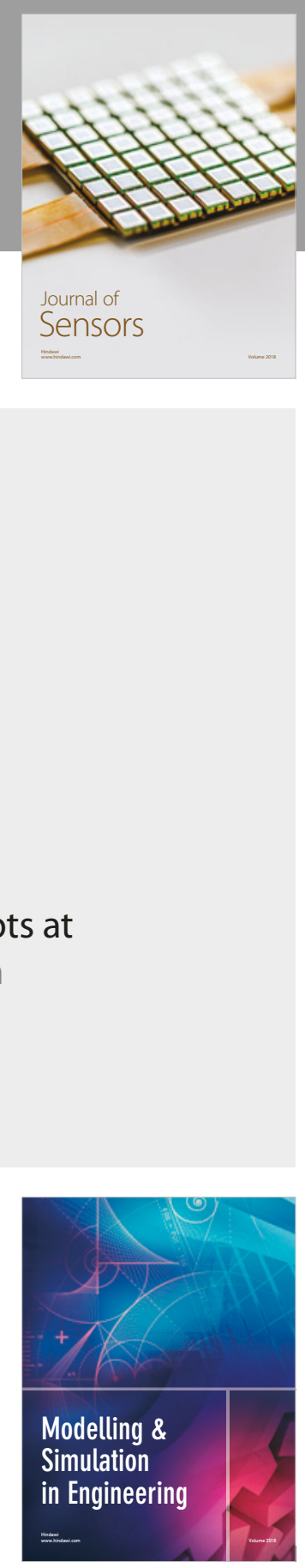

\section{Advances \\ Multimedia}
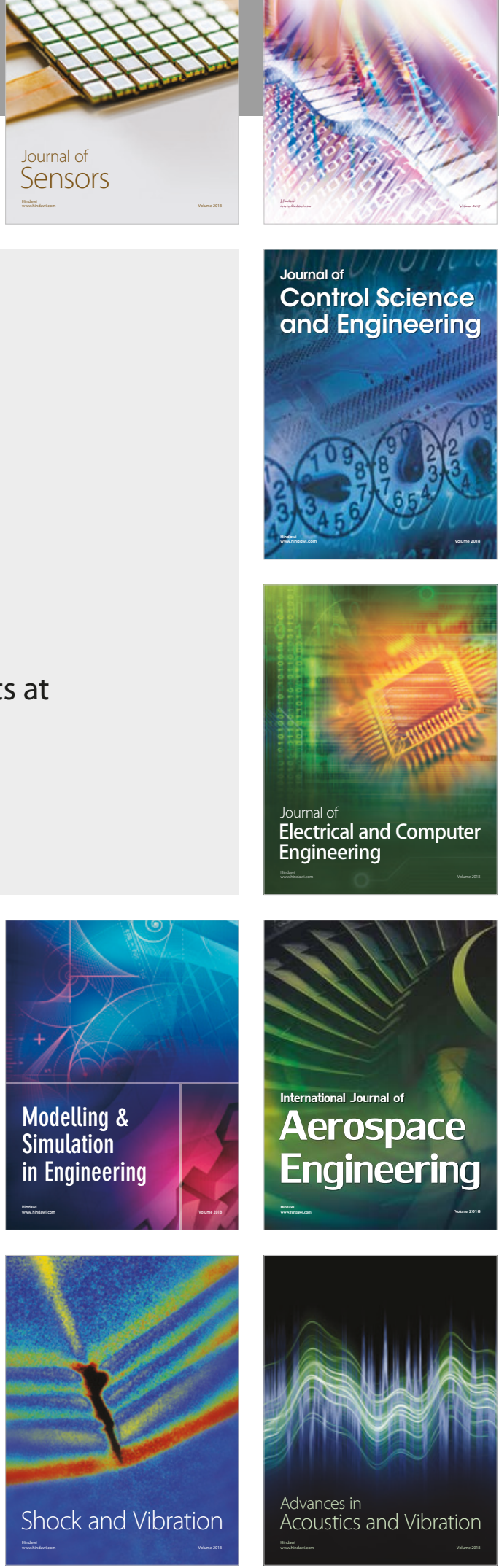